\title{
Novel poss reinforced chitosan composite membranes for guided bone tissue regeneration
}

\author{
Sedef Tamburaci ${ }^{1} \cdot$ Funda Tihminlioglu $^{2}$
}

Received: 23 December 2016 / Accepted: 17 November 2017 / Published online: 1 December 2017

(C) Springer Science+Business Media, LLC, part of Springer Nature 2017

\begin{abstract}
In this study, novel composites membranes composed of chitosan matrix and polyhedral oligomeric silsesquioxanes (POSS) were fabricated by solvent casting method. The effect of POSS loading on the mechanical, morphological, chemical, thermal and surface properties, and cytocompatibility of composite membranes were investigated and observed by tensile test, atomic force microscopy (AFM), Fourier transform infrared spectroscopy (FTIR), thermal gravimetric analysis (TGA), protein adsorption assay, air/water contact angle analysis and WST1 respectively. Swelling studies were also performed by water absorption capacity determination. Results showed that incorporation of Octa-TMA POSS ${ }^{\circledR}$ nanofiller to the chitosan matrix increased the surface roughness, protein adsorption and swelling capacity of membranes. The addition of POSS enhanced significantly the ultimate tensile strength and strain at break of the composite membranes up to $3 \mathrm{wt} \%$ POSS loaded samples. An increase of about $76 \%$ in tensile strength and of strain at break $1.28 \%$ was achieved for $3 \mathrm{wt} \%$ POSS loaded nanocomposite membranes compared with chitosan membranes. The presence of POSS filler into polymer matrix increased the plasma protein adsorption on the surface. Maximum protein capacity and swelling was obtained for $10 \mathrm{wt} \%$ loaded samples. High cell viability results were obtained with indirect extraction of chitosan/POSS composites. Besides, cell proliferation and
\end{abstract}

Funda Tihminlioglu

fundatihminlioglu@iyte.edu.tr

1 Department of Biotechnology and Bioengineering, İzmir Institute of Technology, Gülbahçe Campus, Urla, 35430 İzmir, Turkey

2 Department of Chemical Engineering, İzmir Institute of Technology, Gülbahçe Campus, Urla, 35430 İzmir, Turkey
ALP activity results showed that POSS incorporation significantly increased the ALP activity of Saos-2 cells cultured on chitosan membranes. This novel composite membranes with tunable properties could be considered as a potential candidate for guided bone regeneration applications.

\section{Graphical abstract}
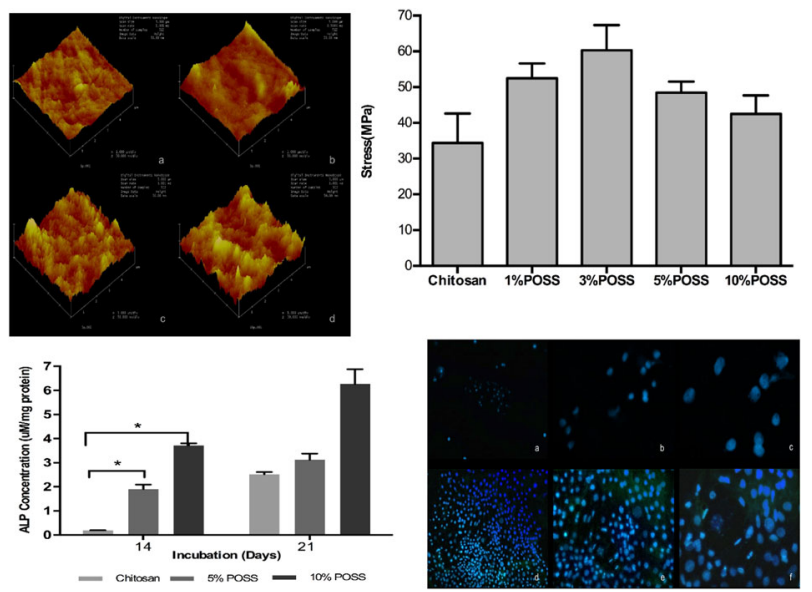

\section{Introduction}

Recent advances in nanotechnology have resulted in the emergence of advanced novel nanomaterials with improved properties capable of being used in several biomedical applications. Nanocomposites have been created with the basis of the assembly of polymers with biological origin and inorganic materials that interact on the nanometric scale. Owing to their excellent structural properties due to the special arrangement at the nanometric level these materials 
have been drawing great interest for versatile applications in important areas such as biomedical applications and regenerative medicine. [1-3]. The growing number of available nanoparticles with controllable size and shape further enables researchers to explore promising polymer nanocomposites with better performance than its pristine polymeric counterparts.

Bone, teeth, shells and nacre are known as major examples of nanocomposites in nature. Bone has a composite structure consisting two phases as inorganic (Hap) and organic (type 1 collagen). Therefore, studies have focused on composite systems and showed that composites compared to the pure polymers indicated improved mechanical, thermal and physicochemical properties distinctly. Besides, inorganic reinforcements have also been used to mimic the composite structure of bone tissue which is mainly consisted of type 1 collagen and Hap crystals to enhance the bioactivity of the material. Researches have focused on modulating cellular function to promote bone tissue regeneration and to mimic the mechanical properties of bone [1-6].

In recent years, many nanosized inorganics such as clay layered silicates, zirconia and carbon nanotubes have been used to prepare polymer/inorganic hybrids [7]. They have an increased number of atoms and crystal grains at their surfaces. Thus, they possess a higher surface area to volume ratio when compared with microscale biomaterials. This enhancement in surface topography increase the surface energy for protein adsorption which is an essential process for cell adhesion on the surface [3].

In this sense, natural polymer composites have been widely preferred for bone tissue engineering applications. Among these polymers, chitosan is widely used due to its porous structure, ease of chemical modifications, biodegradable, biocompatible, antibacterial properties and high affinity to in vivo macromolecules. Furthermore, it has structural similarity to proteoglycans [8]. However, it has some limitations such as low tensile strength and modulus range when compared with natural bone. One approach to overcome this mechanical incompatibility with bone is to reinforce chitosan by an inorganic compound [9-11]. Among those inorganic compounds, silica has been widely used in medicine and nanotechnology in various forms. In recent studies, composites consisting biopolymers and silica nanoparticles show potential in biomedical applications. Since silica particles can improve mechanical properties of polymers by providing enhancement in the structure. Besides, silica content supports bone cell adhesion and bone tissue formation by increasing the bioactivity of composites. Studies showed that silica induced $\mathrm{CaO}$ accumulation on the surface and nucleation of the apatite layer which is an essential step in the formation and mineralization of hard tissues. As a consequence of that, studies have been oriented towards bio-inspired synthesis of new silica-based materials with simple hierarchical structures [12-14].

Polyhedral oligomeric silsesquioxanes (POSS) are specially designed silica with well-defined cage structures, which contain a silicon/oxygen cage (inorganic portion) and hydrocarbon functional groups (organic portions) as hybrid chemical composition intermediate between that of silica $\left(\mathrm{SiO}_{2}\right)$ and silicone $\left(\mathrm{R}_{2} \mathrm{SiO}\right)$. The organic groups form covalent and noncovalent bonds with host-polymer. The size range of POSS in 1-3 $\mathrm{nm}$ size leads to molecular level reinforcements of polymer matrices. Besides, organic groups of POSS provide excellent polymer compatibility of POSS molecules form covalent and non-covalent bonds with host-polymer. POSS containing nanocomposites can be produced by blending POSS into a polymer matrix, by covalently bonding POSS into a polymer backbone, or by using POSS as a pendant group of a polymer [15-19]. POSS nanostructures have been shown as potential nanofillers for biomedical applications because of their enhanced cytocompatibility, physicochemical properties (such as enhanced mechanical and rheological properties) and ability to incorporate with different polymers [9-17]. Interest in POSS incorporated composites is based on the rigid framework of POSS that closely resembles silica and provides a unique molecular level dispersion. This unique structure makes POSS one of the most promising nanomaterials to be used in the structure of different polymers for biomedical applications. POSS-containing nanocomposite can be used as dental composites, biomedical devices, scaffolds as nonbiodegradable or biodegradable materials with tunable degradation rates required for tissue engineering applications [9, 20, 21]. The most promising property of nanostructured POSS lies in its ability to rationally control surface area, volume, and roughness. This control stimulates biological responses at nanoscopic dimensions, such as the initiation cellular bonding and response leading to apatite formation which is the major inorganic component of bone [20-22]. POSS containing copolymers have been developed as nanocomposites for biomedical devices, tissue engineering scaffolds, drug delivery systems, dental applications, and biological sensors with enhanced biocompatibility and physicochemical properties. Recently, a new nanocomposite polymeric material POSS-poly(carbonateurea)urethane (POSS-PCU) has been fabricated (PCU) for several surgical implants, including synthetic heart valve, lacrimal duct, bypass graft, and recently tracheal replacementdue to its remarkable biocompatibility and in vivo biostability [23].

Up to date, a few studies exist in the literature regarding to polymer-POSS composites for bone tissue engineering applications with different material forms. Chew et al., have synthesized and evaluated the thermal, mechanical properties of chitosan-POSS microfiber mats. In addition, they 
investigated the bioactivity of composite mats by observing apatite formation in PBS solution. The tailorable mechanical properties and apatite formation results also suggested that these microfibre composites may be useful for biomedical applications [9]. Ha et al. have fabricated PVAc-POSS composite nanofiber mats for bone tissue regeneration, and their results indicated enhanced formation of apatite layer at the surface with supporting cell adhesion and spreading [24]. Fernandez et al. prepared poly(L-lactic acid)/polyhedral oligomeric silsesquioxane derivatives nanocomposite membranes (PLLA/POSS) using solution casting technique to investigate the effect of POSS type and concentration on the morphological, thermal, mechanical, and surface properties [25]. Nevertheless, in vitro studies of POSS incorporated chitosan composites for bone tissue engineering applications are unknown. Therefore, this study is proposed to design a novel nanocomposite membranes composed of chitosan matrix and polyhedral oligomeric silsesquioxanes (POSS) that can be used as guided bone regeneration membranes for periodontal and maxillofacial applications. The effect of POSS loading on the mechanical, chemical, thermal, and swelling properties, as well as morphological and surface wettability of composite membranes were evaluated. In addition, in vitro cytotoxicity and cellular activities including cell proliferation and cell differentiation were investigated using Saos-2 cell line.

\section{Materials \& methods}

Commercial chitosan with low molecular weight powder was purchased from Sigma-Aldrich and used for preparation of composites. Octa-TMA POSS ${ }^{\circledR}$ (polyhedral oligomeric silsesquioxanes, Hybrid Plastics TM) was used as synthetic silica source for reinforcement. Acetic acid (analytical grade, Sigma-Aldrich) was used as solvent for preparation of composites. WST-1 ready to use cell proliferation reagent (BioVision Inc.) and StemTAG ALP Assay kit (Cell Biolabs Inc.) was used for in vitro assays. DAPI (Cell Signaling Technology) and Alexa Fluor 488 (Thermo Fisher Scientific, Molecular Probes) were used for fluorescence staining.

\subsection{Preparation of chitosan/poss composite membranes}

Chitosan/POSS composite film membranes were prepared by solvent casting method. Chitosan solution with (\% $1 \mathrm{wt})$ was prepared by dissolving chitosan in $1 \% \mathrm{v} / \mathrm{v}$ acetic acid and POSS nanoparticles were dispersed in acetic acid for $24 \mathrm{~h}$, separately. Then, they were mixed and homogenized with sonicator (Misonix Ultrasonic Liquid Processor) for $30 \mathrm{~min}$ at $15^{\circ} \mathrm{C}$ and 35 Amplitude for complete homogenization. $100 \mathrm{ml}$ of each composite dispersion was poured into a petri dish. Film samples were left in ambient laboratory condition until drying. After initial drying in ambient conditions, samples were dried in a vacuum oven at $37^{\circ} \mathrm{C}$ for $48 \mathrm{~h}$ to remove residual solvent from the membranes completely. For all membranes, thickness was measured by micrometer caliper and found in the range of $50-70 \mu \mathrm{m}$.

\subsection{Characterization of chitosan/poss composite membranes}

\subsubsection{Atomic force microscopy (AFM)}

Atomic force microscopy (AFM) images of the membranes were taken by using Nanoscope (Digital Instruments Inc., USA). Point probe cantilever tip was used in tapping mode by the accompanying software to determine the surface morphology and roughness of the prepared composite membrane surfaces. The AFM topographic data have been quantitatively analyzed for each sample on three scanned areas of $5 \times 5 \mu \mathrm{m}$. Surface roughness was calculated as the root mean square average of the surface height deviations from the mean image data plane $(\mathrm{Rq})$.

\subsubsection{Surface wettability}

The static water contact angles of pure chitosan and all composite membranes were measured with optical tensiometer (Attension Theta Lite). Samples $(1 \mathrm{~cm}$ width and 5 $\mathrm{cm}$ length) for each group were prepared before the measurement. Ultrapure water was used as liquid phase and drop size was set to $6 \mu \mathrm{l}$. All data presented were determined as the mean values of five independent measurements.

\subsubsection{Protein adsorption assay}

In order to determine the quantities of proteins adsorbed on chitosan/ POSS composite membranes, the membranes were incubated in protein solution. Experiment was carried out in 24 well plates. Before the incubation process, the samples of the composite membranes were treated by PBS for $30 \mathrm{~min}$. 0.1\% Bovine serum albumin (BSA) was used as a model protein and $1 \mathrm{ml}$ protein solution was added into each well. The sample specimens were incubated at $37^{\circ} \mathrm{C}$ for $24 \mathrm{~h}$ and $48 \mathrm{~h}$. The amount of adsorbed proteins on membranes was determined by a commercial protein assay kit, BCA (Pierce, Rockford, IL), using bovine serum albumin (BSA) as standards [26]. Protein adsorbed on membrane surface was determined by subtraction of free BSA from total protein amount used for incubation. 


\subsubsection{Fourier transform infrared spectroscopy (FTIR)}

The chemical structure and characteristic peaks of POSS nanocages, chemical bonding between POSS nanocage and chitosan matrix were analyzed by fourier transform infrared spectroscopy with ATR instrument (Shimadzu FTIR-8400 s) at wavelengths ranging from 4000 to $400 \mathrm{~cm}^{-1}$ at resolution of $4 \mathrm{~cm}^{-1}$. Alterations on bond structures of composite membranes were investigated.

\subsubsection{Thermal gravimetric analysis (TGA)}

Thermogravimetric analysis (Perkin Elmer Diamond TG/ DTA) was used to evaluate the thermal stability of the nanocomposites. Analyses were carried out in a nitrogen atmosphere from 30 to $650^{\circ} \mathrm{C}$ at a heating rate of $10^{\circ} \mathrm{C} / \mathrm{min}$.

\subsubsection{Water absorption capacity of chitosan/poss composite membranes}

Swelling test is performed in order to obtain swelling behavior of the prepared chitosan and chitosan/POSS composite membranes. Experiments were performed thrice and water absorption capacity was measured with three samples for each group. Briefly, dry samples were firstly weighted and noted as $\mathrm{W}_{\mathrm{d}}$ samples. Then, they were soaked in 1X PBS (phosphate buffered saline) (PBS) at $37^{\circ} \mathrm{C}$ for 1 h, 24 and $48 \mathrm{~h}$ periods. Following the incubation, they were removed and wiped out using filter paper to remove excess liquid. Then, wet samples $\left(\mathrm{W}_{\mathrm{w}}\right)$ were weighted. Swelling ratio (SR) (or degree of swelling) was then determined with the following equation: [27]. The results were given as mean $\mathrm{SR} \pm$ standard deviation.

$$
\mathrm{SR}=\frac{\mathrm{W}_{\mathrm{w}}-\mathrm{W}_{\mathrm{d}}}{\mathrm{W}_{\mathrm{d}}}
$$

\subsubsection{Mechanical characterization of chitosan/poss composite membranes}

Mechanical properties of the chitosan based membranes $(1 \mathrm{~cm}$ width and $5 \mathrm{~cm}$ length) were measured by tensile testing equipment (TA XT Plus Texture analyzer) with a 5 kgf load cell according to the ASTM D882-02 standard. Thickness of tested membranes was measured with an electronic digital micrometer (Mitutoyo) with $1 \mu \mathrm{m}$ sensitivity by taking the average of four different points. Initial gauge length and cross-head speed were set as $100 \mathrm{~mm}$ and $10 \mathrm{~mm} / \mathrm{min}$. Ultimate tensile strength, strain at break, and Young's modulus of the samples were calculated from strain-stress data. The resulting data were reported as the average of at least five samples.

\subsection{In vitro studies}

\subsubsection{Cytotoxicity and cell proliferation studies}

In vitro cytotoxicity of chitosan/POSS composite membranes on $3 \mathrm{~T} 3$ fibroblast and Saos-2 osteosarcoma cell lines was determined by indirect extraction method (ISO 10993; $24 \mathrm{~h}$ extraction), WST 1 colorimetric assay which is based on an intermediate electron acceptor reagent penetrating viable cells and being reduced at the cell surface. Therefore, the amount of formazan dye formed directly correlates to the number of metabolically active cells in the culture [28]. Cell lines were maintained in DMEM supplemented with 2 $\mathrm{mM}$ L-glutamine, $10 \%$ fetal bovine serum, $100 \mu \mathrm{g} / \mathrm{ml}$ streptomycin and $100 \mathrm{U} / \mathrm{ml}$ penicillin in an atmosphere of $5 \% \mathrm{CO}_{2}$ at $37^{\circ} \mathrm{C}$. Subcultivation was performed every $48 \mathrm{~h}$. Experiments were performed in triplicate. Optical density was determined in the absorbance of $440 \mathrm{~nm}$. Cell viability was calculated by using the formula: Cell viability: $100 \% \times$ (Average absorbance value of treated cells/ Average absorbance value of control cells).

In vitro cell proliferation on chitosan/POSS composite membranes was also assessed by WST-1 assay. Specimens were sterilized with $70 \%$ ethanol for $24 \mathrm{~h}$, washed with $1 \mathrm{X}$ PBS and conditioned with cell culture medium for $2 \mathrm{~h}$ before cell seeding. 50000cell/well were seeded on membranes $(1 \times 1 \mathrm{~cm})$ with $20 \mu \mathrm{l}$ inoculation volume. Membranes were incubated at $37{ }^{\circ} \mathrm{C} / 5 \% \quad \mathrm{CO}_{2}$ with $1 \mathrm{ml}$ cell culture medium. Cell culture medium was changed twice a week. Cell proliferation on membranes was determined with WST-1 viability assay for different incubation times $(1,3,5,7,10$ and 14 day). Cell spreading and proliferation on membrane surface was also proven by fluorescence microscopy with DAPI/Alexa fluor 488 phalloidin staining.

\subsubsection{Cell differentiation by alkaline phosphate activity $(A L P)$}

ALP is based on hydrolysis of p-nitrophenyl phosphate (pNNP) to p-nitrophenol, the conversion of p-nitrophenol is directly related proportional to ALP. ALP activity of Saos-2 cells cultured on membranes were quantified by fluorometric StemTAG ${ }^{\text {TM }}$ ALP activity kit at 14th and 21th day incubation periods. Cell culture medium was aspirated and scaffolds were washed.with cold PBS solution. Cells were incubated in cell lysis buffer for $20 \mathrm{~min}$ at $4{ }^{\circ} \mathrm{C}$ and centrifuged at $12,000 \times g$. Supernatant was used as cell lysate. $50 \mu \mathrm{l}$ cell lysate and $50 \mu \mathrm{l} 1 \times$ substrate solution (pNNP) were incubated at $37^{\circ} \mathrm{C}$ for $30 \mathrm{~min}$. The absorbance of mixture was measured fluorescence plate reader at $480 \mathrm{~nm}$ excitation and $520 \mathrm{~nm}$ emission. BCA assay was also performed in order to determine the protein concentration of the cell lysate. 


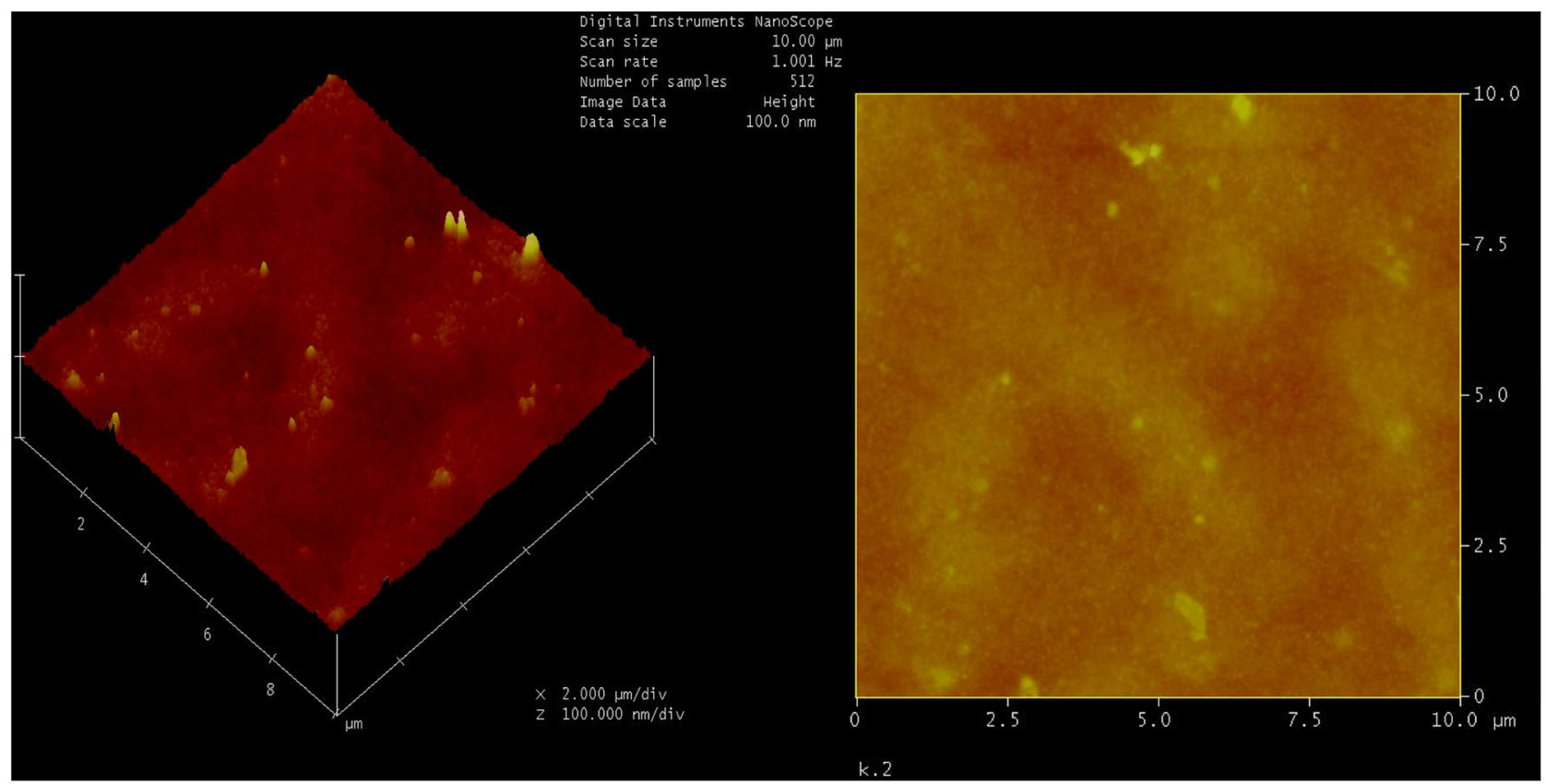

Fig. 1 AFM images of pure chitosan membrane. Topography (left) and phase (right), the scan size: $5 \times 5 \mu \mathrm{m}$

\subsection{Statistical analysis}

All experiments were repeated thrice and samples were evaluated in triplicate. The experimental data is expressed as the standard deviation of the mean (SEM). Statistical analysis of mechanic test and swelling data were carried out using One-way ANOVA with Tukey's multiple comparison test $(p<0.05)$. Statistical analyses of protein adsorption and in vitro studies were carried out using two way ANOVA with Tukey's multiple comparison test. Statistical significance was indicated by $p<0.05$.

\section{Results}

\subsection{Surface properties}

\subsubsection{Atomic force microscopy}

Figures 1, 2 and 3 show the AFM topographic and phase images of the chitosan and chitosan/POSS composite membranes, respectively. As it can be seen in Figs. 1 and 2, the AFM images show differences in surface properties of composite membranes compared to chitosan. For the pure chitosan membranes, the surface was essentially smooth, showing few topographic features. The surface morphology of composites depends on the POSS concentration. Surface roughness increased from 3.58 to $9.54 \mathrm{~nm}$ (Fig. 2, Table 1). The surface topography results showed that at low POSS loadings, few small protruding regions were observed, however, at high loadings (5 and $10 \% \mathrm{wt}$ ), more concentrated protruding regions were obtained. The bright spots in phase images corresponding to POSS particles showed good dispersion of POSS particles in chitosan up to $3 \mathrm{wt} \%$ of POSS (Fig. 3).

\subsubsection{Surface wettability}

Static air-water contact angle data of composite membranes were measured and tabulated in Table 2. Incorporation of POSS into chitosan did not change the surface hydrophilicity significantly. However, all membranes showed hydrophilic surface properties with contact angle data below $90^{\circ}$. Thus, surface of the membranes was considered to be suitable for protein and cell adhesion.

\subsubsection{Protein adsorption assay}

Protein adsorption on the samples was performed for 24 and $48 \mathrm{~h}$. It is evident from Fig. 4 that POSS incorporation enhanced protein adsorption capacity of the chitosan surface compared to chitosan control and chitosan/POSS membranes adsorbed protein gradually with time. Maximum protein adsorption was observed on composite membranes with $10 \%$ wt POSS for $48 \mathrm{~h}$.

\subsection{FTIR analysis}

FT-IR spectra of Octa-TMA POSS nanocage, chitosan and chitosan-POSS membranes are shown in Fig. 5. 


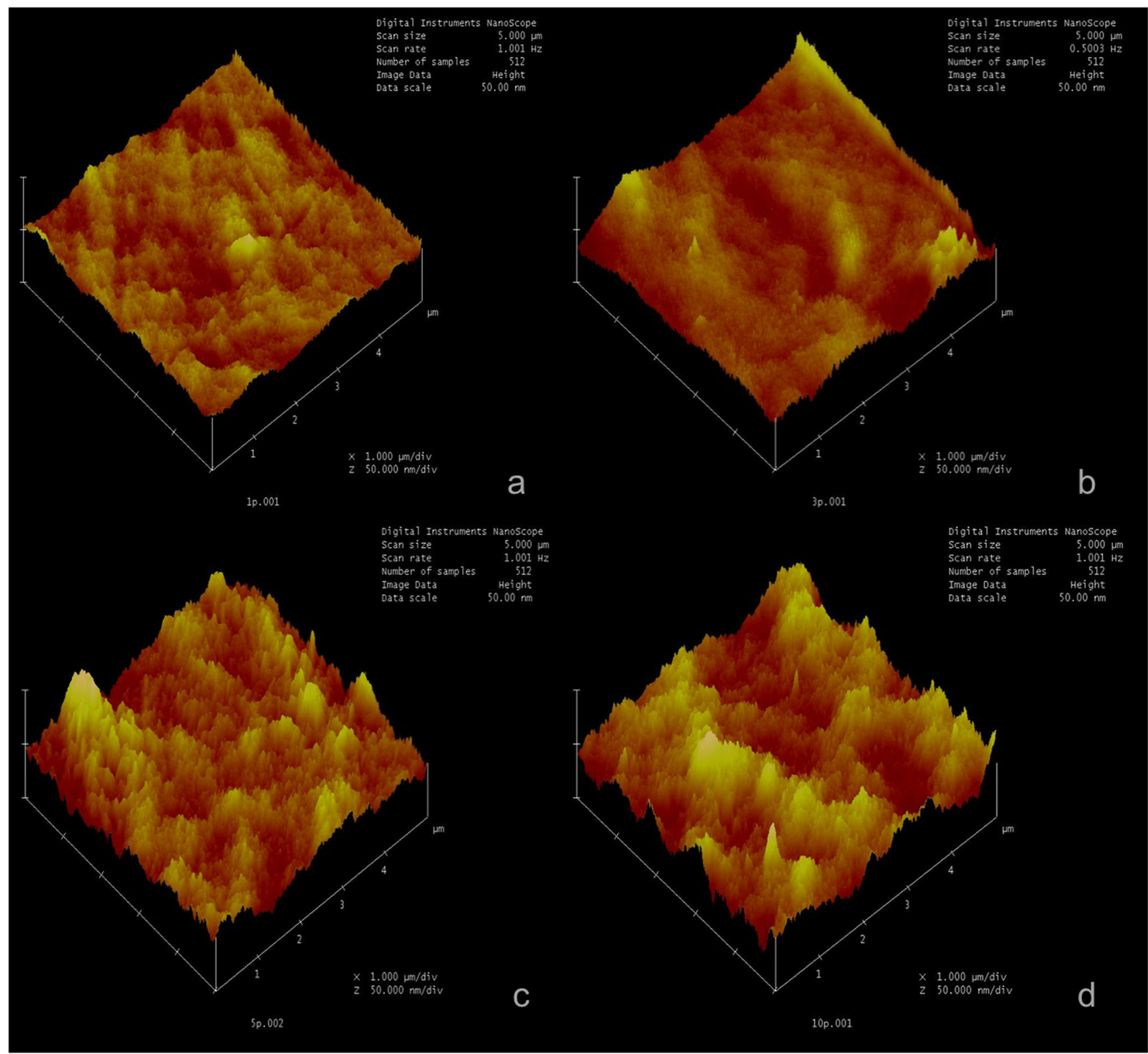

Fig. 2 Atomic force microscopy (AFM) images of Chitosan-POSS composite membranes showing surface topography: 1\% POSS (a), 3\%POSS (b), 5\% POSS (c) and $10 \%$ POSS (d) content, respectively. Surface roughness is induced by agglomeration of POSS nanocages on the surface

TMA-POSS nanocage is composed of rigid $\mathrm{Si}-\mathrm{O}$ cage containing eight $-\mathrm{ON}\left(\mathrm{CH}_{3}\right)_{4}$ groups in each of the corners. FTIR spectrum result of TMA-POSS (Fig. 5c) shows that the pure POSS has a strong and symmetric $\mathrm{Si}-\mathrm{O}-\mathrm{Si}$ stretching absorption band at 1070-1090 and 585-600 $\mathrm{cm}^{-1}$, which are assigned to $\mathrm{Si}-\mathrm{O}-\mathrm{Si}$ asymmetric stretching and bending vibrations, respectively which are the characteristic absorption peaks of silsesquioxane inorganic cages. The absorbing peaks at $1680,1480-1490 \mathrm{~cm}^{-1}$ are attributed to the stretching vibration of organic $\mathrm{R}$ group (tetramethylammonium) of POSS nanocage for MeNO and MeN groups, respectively (Fig. 5c). As seen in Fig. 5b, chitosan showed a band appearing in the spectrum were due to stretching vibrations of $\mathrm{OH}$ groups in the range from of
3547 to $2850 \mathrm{~cm}^{-1}$. All characteristic chitosan peaks appeared in the composite spectrum. Typical bonds of POSS molecules are also observed in the POSS incorporated chitosan composite structure (Fig. 5a, b). FTIR analysis of chitosan/POSS composite membranes showed $\mathrm{Si}-\mathrm{O}-\mathrm{Si}$ bond peaks at $580-660$ and $1010 \mathrm{~cm}^{-1}$ with stretching and bending vibrations, respectively.

\subsection{Thermal gravimetric analysis}

Figure 6 shows TGA thermograms of the chitosan and the composite membranes with different POSS loadings. The TGA results indicate that composite membranes exhibited quite similar TG trends. Initial weight loss of $15 \%$ was 


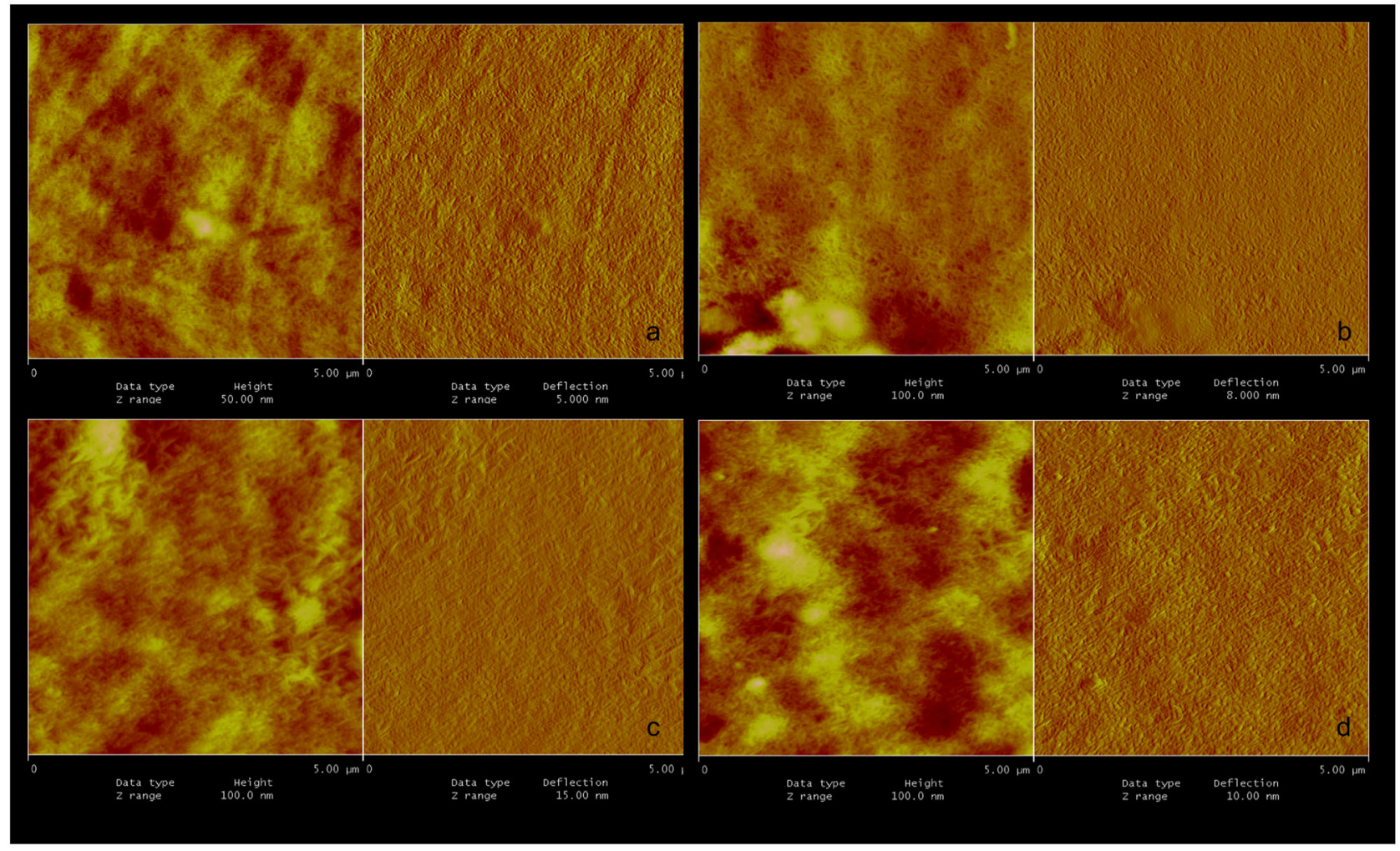

Fig. 3 AFM phase images of chitosan/POSS composite membranes: 1\% POSS (a), 3\% POSS (b), 5\% POSS (c) and 10\% wt POSS (d)

Table 1 Surface Roughness of pure chitosan and chitosan/POSS composite membranes

\begin{tabular}{ll}
\hline Composite Groups & Roughness (Rq) (nm) \\
\hline Chitosan & $3.58 \pm 0.1$ \\
Chitosan-1\% POSS & $3.85 \pm 0.65$ \\
Chitosan-3\% POSS & $6.17 \pm 1.4$ \\
Chitosan-5\% POSS & $6.50 \pm 0.3$ \\
Chitosan-10\% POSS & $9.54 \pm 1.04$ \\
\hline
\end{tabular}

Table 2 Water contact angle of chitosan and composite membranes. The data of water contact angle was shown as the mean \pm SD for five measurements

\begin{tabular}{ll}
\hline Membrane groups & Contact angle \\
\hline Chitosan & $77.98^{\circ} \pm 5.6$ \\
Chitosan-5 \% POSS & $77.87^{\circ} \pm 2.24$ \\
Chitosan-10\% POSS & $80.20^{\circ} \pm 1.40$ \\
\hline
\end{tabular}

observed for all composites at $100^{\circ} \mathrm{C}$, which was attributed to vaporization of water and solvents from the samples. Second weight loss attributing depolymerization of composites was observed between 300 and $315^{\circ} \mathrm{C}$. No trend was observed regarding the effects of POSS content on the thermogravimetric properties of the composites.

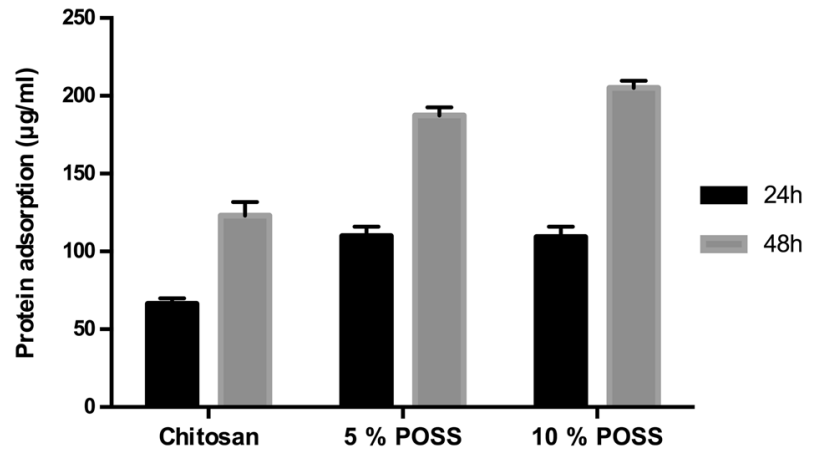

Fig. 4 Adsorption of BSA on chitosan/POSS composite membranes for 24 and $48 \mathrm{~h}$ periods

\subsection{Mechanical properties}

The effect of POSS addition on the mechanical properties of the chitosan nanocomposite membranes were investigated. The native chitosan had a tensile strength of $34.37 \mathrm{MPa}$ and strain at break of $0.90 \%$ (Fig. 7a, b). Tensile strengths of the nanocomposite membranes increased significantly with increasing amount of POSS attaining a maximum value of $60.28 \pm 7.07 \mathrm{MPa}$ at $3 \%(\mathrm{w} / \mathrm{w})$. An increase of about $76 \%$ in tensile strength and of strain at break $1.28 \%$ was achieved for $3 \mathrm{wt} \%$ POSS loaded nanocomposite membranes 


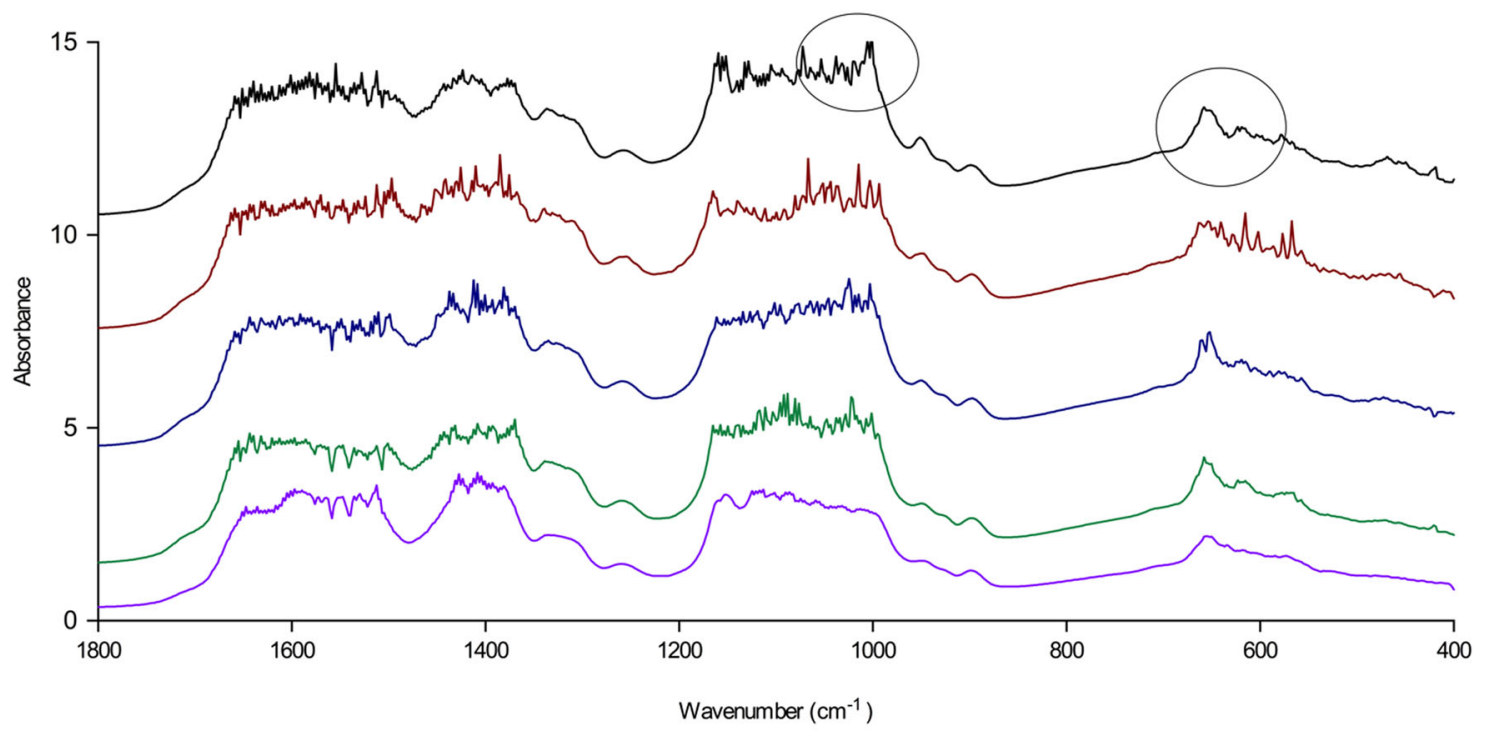

(a)

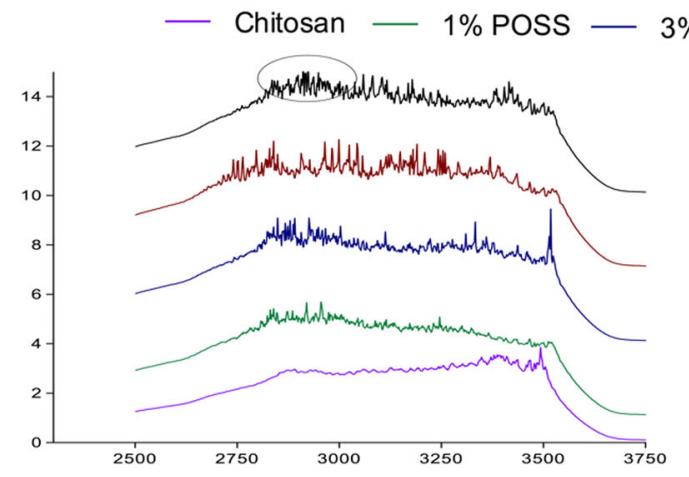

(b)

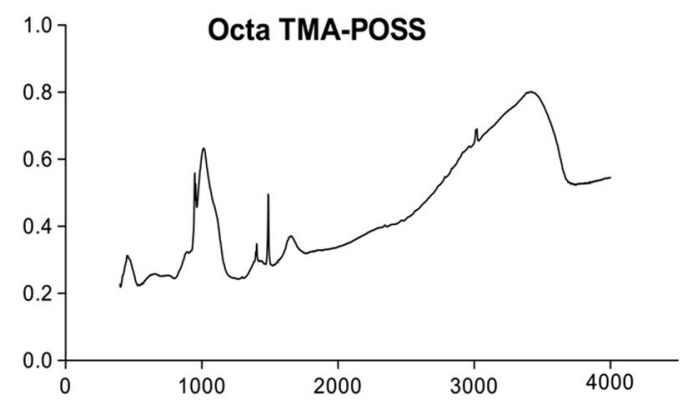

(c)

Fig. 5 FTIR spectra of and chitosan/POSS composites (a, b) and Octa-TMA POSS nanocages (c)

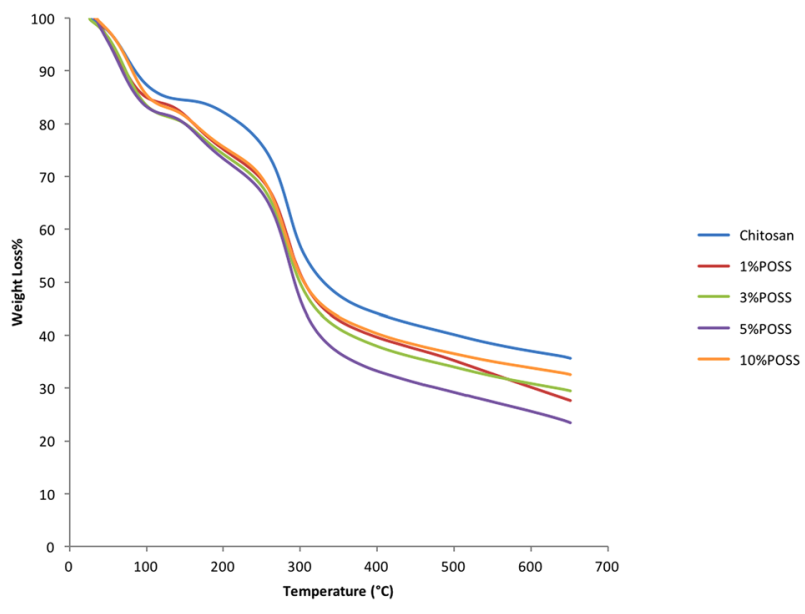

Fig. 6 TGA thermogram of chitosan/POSS composite membranes under nitrogen environment

compared with native chitosan membranes as seen in Fig. 8a, b. POSS incorporation increases the biomechanical properties of chitosan matrix up to $3 \%$. The decrease above this concentration may lead from the possible agglomeration of POSS nanocages in chitosan matrix because POSS particles generally have tendency to interact and bond eachother. In the case of a Young Modulus, no appreciable difference was observed in the composites. The modulus increased slightly up to $3 \mathrm{wt} \%$ POSS content (Fig. 7c), however the reduction was observed for 5 and $10 \mathrm{wt} \%$ POSS loaded membranes is consistent with the tensile strength data. Statistically, no significant difference was observed between groups.

\subsection{Swelling properties}

Water absorption capacity of chitosan and composite membranes were determined for $24 \mathrm{~h}$ period. Figure 8 shows the effect of POSS loading on the swelling ratio of chitosan membranes. Except 1\% POSS group, all chitosan/ POSS composite groups showed higher swelling ratio. 10 wt\% POSS loaded composite membranes showed the highest swelling ratios for $24 \mathrm{~h}$ periods. 


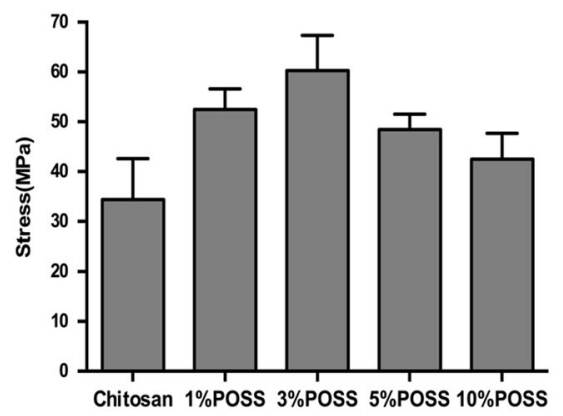

(a)

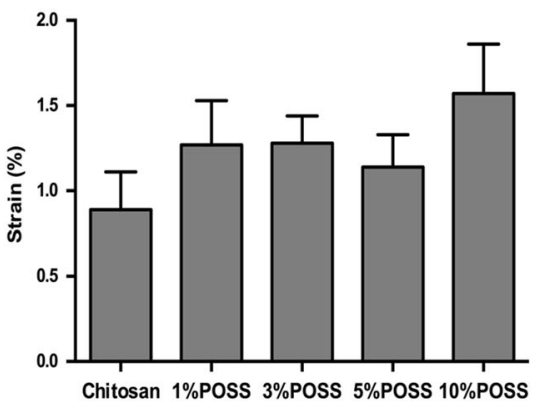

(b)

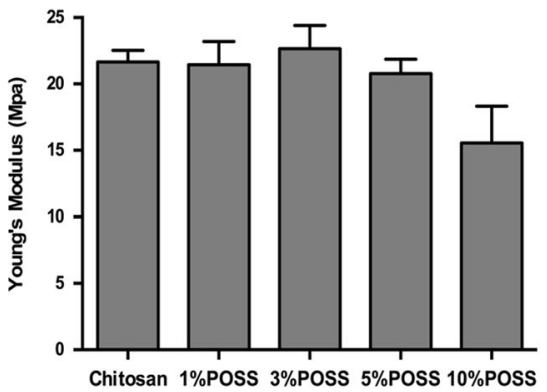

(c)

Fig. 7 Maximum stress (a), strain\% (b) and Young's moduli c data of chitosan/POSS composites with increasing POSS content

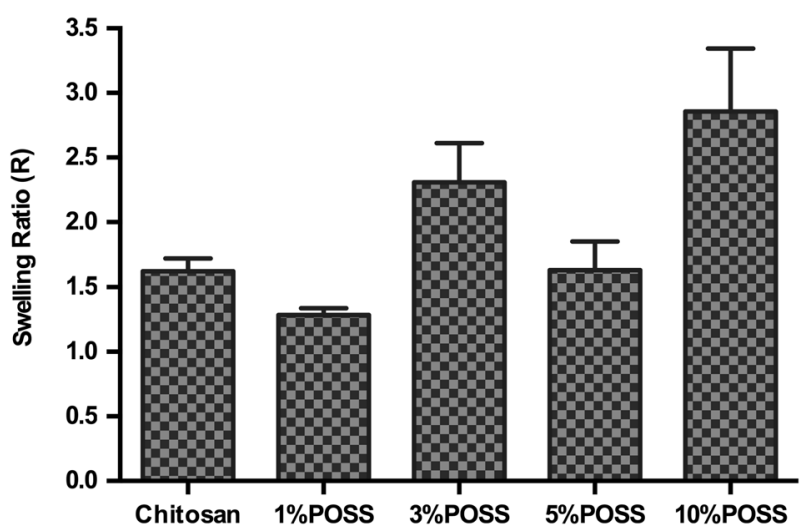

Fig. 8 Swelling ratio of chitosan/POSS composites with increasing POSS contents

\subsection{Cytocompatibility of chitosan/poss membranes}

Cytotoxicity results indicated that chitosan/POSS membranes didn't show any cytotoxic effect on 3T3 fibroblast and Saos-2 osteosarcoma cell lines. High cell viability results were obtained for all incubation periods (Fig. 9a, b). No significant difference was observed between groups for 3 T3 cell viability results $(p<0.05)$. Saos- 2 cell viability results showed significant differences between chitosan and $10 \%$ POSS groups for $72 \mathrm{~h}(\mathrm{p}<0.05)$.

Figure 10 shows the absorbance values determined by WST 1 assay for Saos-2 osteoblastic cell proliferation on chitosan/POSS membranes. Absorbance results are normalized to control group as cell viability \%. Results showed that the cells on both chitosan and chitosan composites showed similar \% cell viability for up to 5th day of incubation. However, POSS incorporation increased cell proliferation on chitosan membranes after 7 th day of incubation. Cell proliferation differences were significant between chitosan and POSS groups for 7, 10 and 14 day incubation periods $(p<0.05)$.

Osteogenic differentiation of Saos-2 cells cultured on composites was determined by ALP activity assay. Figure 11 shows the ALP activity of Saos-2 cells on

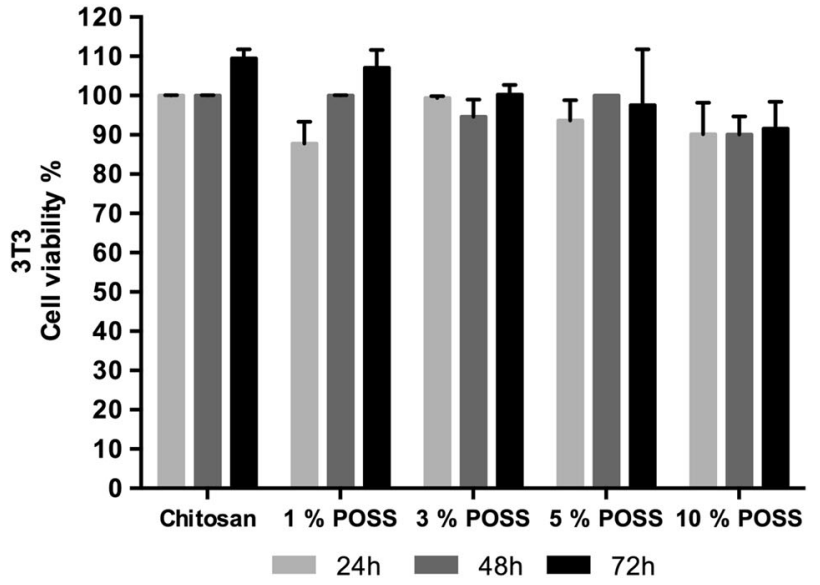

(a)

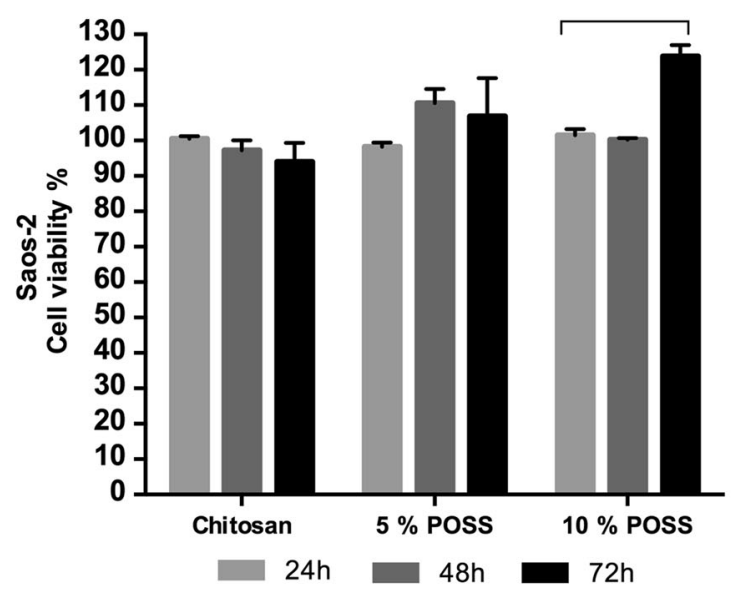

(b)

Fig. 9 In vitro cytotoxicity results of chitosan/POSS composite membranes on $3 \mathrm{~T} 3$ (a) and Saos-2 cell lines (b)

chitosan/POSS nanocomposites compared with chitosan membrane for incubation periods of 14 and 21 days. Results showed that POSS incorporation increased the ALP activity of cells compared to chitosan membrane and the values increased remarkably with an increase in POSS content for both incubation periods. Statistical results indicated that 


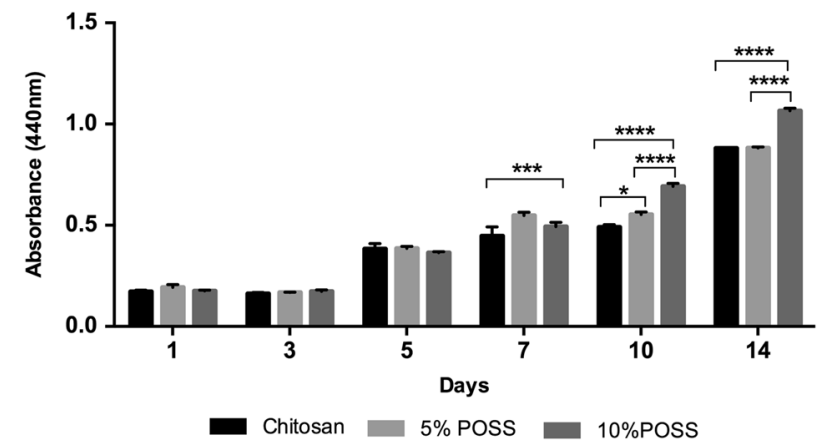

Fig. 10 Saos-2 proliferation on chitosan/POSS composite membranes

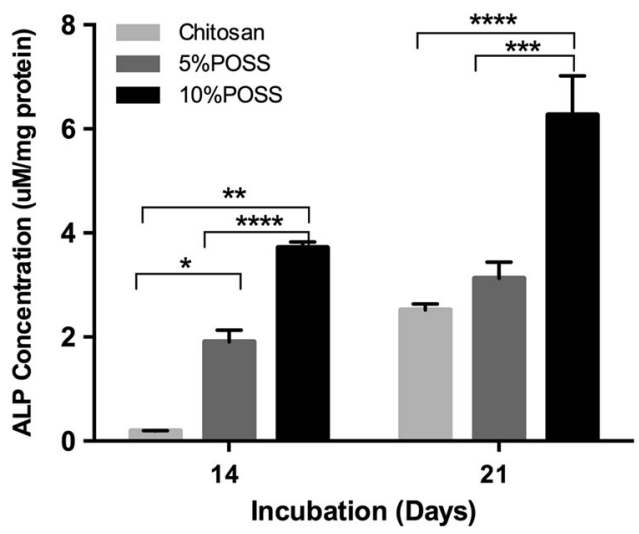

Fig. 11 ALP activity of Saos-2 cells cultured on chitosan/POSS composite membranes for 14 and 21 days

significant difference was observed between the ALP activity of chitosan and POSS groups for both 14th day and 21th day.

Figure 12 illustrates fluorescence microscopy images of the Saos- 2 cells cultured on chitosan and $5 \mathrm{wt} \%$ POSS loaded chitosan membranes for 7 days by staining with dapi/phalloidin). As seen from the micrographs, higher cell spreading was observed on chitosan/POSS membranes prominently. Besides, cell proliferation is found to be higher on chitosan/POSS composite membrane compared to control chitosan membrane.

\section{Discussion}

The interaction between the nanofiller and the polymer matrix specify reinforcement level in the nanocomposite. Hence, optimum performance is obtained when the reinforcement is uniformly dispersed in the structure and interact strongly with the organic matrix [17]. AFM analysis was performed in order to observe effect of POSS on the dispersion /interaction with polymer matrix and surface topography (Figs. 1-3). When compared with pure chitosan membrane, POSS incorporation increased the surface roughness which is an important phenomenon for cell adhesion and proliferation in tissue regeneration (Table 1). The wet contact angle of materials has been considered to be one of the physical parameters which determine the affinity between cells and the material surface. Generally, materials with hydrophilic surface are considered to be appropriate for cell proliferation [29]. However, studies on the interaction between cells and monolayers indicated that protein adhesion which initiated the cell-surface interaction was limited on highly hydrophobic and hydrophilic surfaces. Results showed that moderately wettable surfaces induced cell adhesion and proliferation [30, 31]. Static contact angle measurement results indicated that chitosan/ POSS membranes possesed a moderately hydrophilic surface (Table 2). However, the effect of increasing POSS content on contact angle could not be observed implicitly due to the roughness factor. The contact angle hysteresis generally arises from surface roughness and these type of surfaces are difficult samples for static contact angle measurements. In such cases the actual microscopic variations of slope on the surface create barriers that pin the motion of the contact line and alter the macroscopic contact angles [32]. Thus, the enhancing effect of POSS incorporation on swelling behaviour could not be observed on surface hydrophilicity.

Protein adsorption was determined by BCA assay. Protein adsorption is most important process for initiation of cell-matrix interaction via integrins and regulation of cell migration, spreading and proliferation [17]. In our study, results indicated that POSS incorporation enhanced the protein adsorption on chitosan surface and chitosan/ POSS membranes adsorbed protein gradually with time (Fig. 4).

FT-IR analysis of Octa-TMA POSS nanocage, chitosan and chitosan-POSS membranes were carried out to determine the chemical interaction between chitosan matrix and POSS nanocages. The $\mathrm{OH}$ stretching vibrations of the $\mathrm{SiOH}$ groups absorb in the range of $3700-3200 \mathrm{~cm}^{-1}$. Si-O bands are seen at $950-1020 \mathrm{~cm}^{-1}$. Characteristic peaks belonging to R (tetramethyl ammonium) group of POSS are obtained at 3010, 1680, 1480-1490 $\mathrm{cm}^{-1}$ (Fig. 5c) similar to Liu et al. [33]. Basic characteristic absorption peaks of chitosan were seen in the range of $1680-1480 \mathrm{~cm}^{-1}$ was related to the vibrations of carbonyl bonds $(\mathrm{C}=\mathrm{O})$ of the amide group and to the vibrations of protonated amine group [34]. Absorption in the range from 1188 to $964 \mathrm{~cm}^{-1}$ has been attributed to vibrations of $\mathrm{C}-\mathrm{O}$ group [35]. The small peaks around at 883 and $923 \mathrm{~cm}^{-1}$ correspond to wagging of saccharide structure of chitosan (Fig. 5a) [36, 37]. FTIR analysis results indicated that chitosan/POSS composite membranes showed slightly increasing $\mathrm{Si}-\mathrm{O}-\mathrm{Si}$ peaks at 660 and $\mathrm{Si}-\mathrm{O}$ peaks at $1000-1100 \mathrm{~cm}^{-1}$ with increasing POSS content. As stated in 

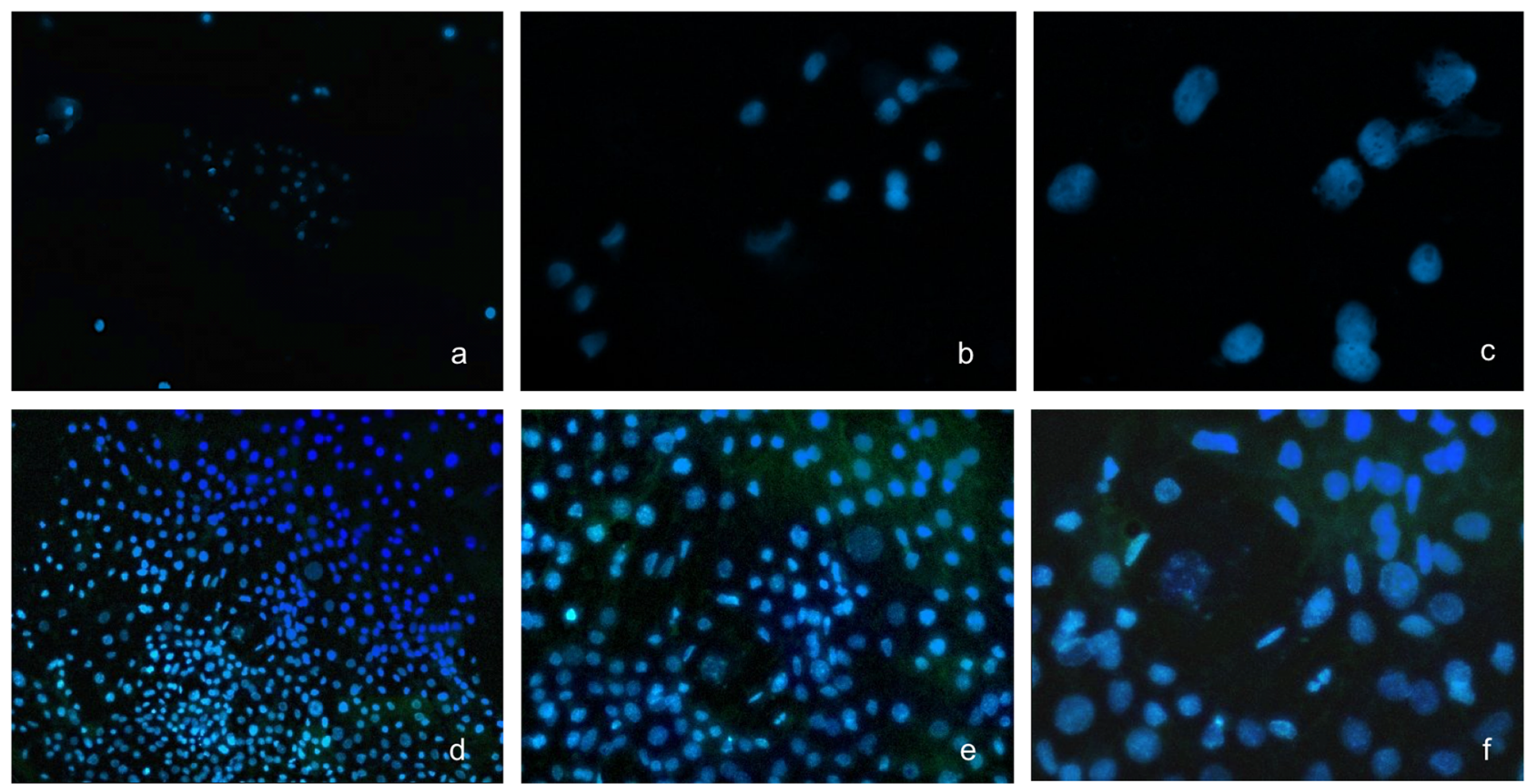

Fig. 12 Fluorescence microscopy images of Saos-2 cells cultured on chitosan membranes (a, b, c) and chitosan-5\% POSS loaded nanocomposite membranes $(\mathbf{d}, \mathbf{e}, \mathbf{f})$ for 7 days

Fig. $5 b$, shifts in $2850-3000 \mathrm{~cm}^{-1}$ showed the interaction between NH groups of chitosan and methyl groups of POSS.

Thermogravimetric analysis (TGA) was used to evaluate and compare thermal stabilities and decomposition behavior of composite membranes. Chitosan, like other polysaccharides, thermally decomposes to carbon-rich materials at high temperatures under inert atmospheres [38]. The thermal stability of POSS-containing nanocomposites depends on POSS-polymer surface interactions and the amount of POSS in polymer matrix. Initial weight loss was observed for all composites at $100^{\circ} \mathrm{C}$. The presence of octamethyl-POSS did not affect the degradation mechanism as well as of degradation temperature of chitosan composites because of the its lower volatilization temperature $\left(261{ }^{\circ} \mathrm{C}\right)$ when compared to the depolymerization temperature of chitosan $\left(300-315^{\circ} \mathrm{C}\right)$ (Fig. 6). Although the thermal degradation of the composites begins from about $150{ }^{\circ} \mathrm{C}$, the main decomposition temperature remains at about $315^{\circ} \mathrm{C}$. The initial degradation starts at around $300^{\circ} \mathrm{C}$. The second weight loss for all composites occurred between 300 and $315^{\circ} \mathrm{C}$ related to thermal degradation of polymer structure. Generally, this temperature varies with the molecular weight, the deacetylation degree of chitosan and the heating rate employed [39].

Reinforcements generally used for improving the mechanical strength and modulus of polymers. The effect of these reinforcements on mechanical properties depends on its size, shape, and dispersion in polymer matrix [17]. Chitosan is widely used as bone tissue scaffold with its unique properties. However, main disadvantage of chitosan is its mechanical limitations (low tensile strength). Since POSS nanocage used in this study is hydrophilic, it has good compatibility with chitosan, therefore, it is expected that POSS incorporation can improve the tensile strength of chitosan matrix. In this study, tensile strengths of the nanocomposite membranes increased significantly with increasing amount of POSS up to $3 \%(\mathrm{w} / \mathrm{w}$ ) (Fig. 7). However, after $3 \mathrm{wt} \%$ of POSS loaded samples, mechanical properties decreased which could be resulted from the tendency of POSS particles lead to agglomeration in polymer matrix. Similarly, Chew et al. indicated that POSS incorporation to chitosan matrix improved the mechanical strength up to a 7\% POSS concentration [9]. It is also reported that, POSS addition at higher concentrations effects the dispersion of POSS nanoparticles and POSS nanoparticles coalesce among the chitosan, acting as a filler with little or low adhesion to the chitosan matrix [40].

Water absorption capacity has an important role on material-tissue interactions. Biomaterials with appropriate swelling properties easily absorb body fluids when engrafted to the defect site. Swelling of the material depends on the surface as well as microstructure of the material. POSS incorporation increased the swelling of the material indicating the hydrogel network had been highly expanded due to the chemical reaction between the functional group of POSS and the polymer constituents. As shown in Fig. 8, it was found that except $1 \mathrm{wt} \%$ POSS loading, the addition of POSS resulted in a substantial POSS concentration- 
dependent increase in swelling ratio as in good agreement with the literature [41].

Bioactivity of composite membranes were determined by in vitro cell culture studies. In order to examine the cytotoxicity, composite membranes were extracted for $24 \mathrm{~h}$ in culture medium at $37{ }^{\circ} \mathrm{C}$ according to ISO 10993 standards and cell viability \% was determined at 24,48 and $72 \mathrm{~h}$. Chitosan/POSS membranes didn't show any cytotoxic effect on 3T3 and Saos-2 cell lines (Fig. 9a, b). Osteoblastic cell proliferation on chitosan/POSS membranes was determined by WST-1 assay. Saos-2 proliferation on chitosan/ POSS nanocomposite membranes was found to be significantly higher than that on the chitosan. Therefore, it could be said that silica content of POSS nanocages affected cell viability positively (Fig. 10). The ALP activity is an important marker for differentiation of pre-osteoblasts to matur osteblasts before biomineralization process of bone regeneration, that was determined for Saos-2 cells cultured on composite membranes. Results indicated that POSS incorporation significantly increased the ALP activity of cells for 14 day incubation (Fig. 11). Fluorescence micrographs proved that altered surface topography with POSS incorporation promoted cell adhesion on membranes (Fig. 12).

Although in vitro studies shows the potential of the biomaterials by defining the cytocompatibility, they can not determine the biocompatibility of the material in a living organism. A biocompatible material implanted in a living organism does not have a negative effect on tissues and biocompatible polymeric materials can be classified as biotolerant on body tissues [42]. Biotolerance of the material is an important factor for tissue response at the defect site [43]. Most important host tissue response to biomaterials and their evaluation are non-specifc inflammation and specific immunological reactions, systemic effects, bloodmaterials interactions, tumor formation, and infection [44]. The inflammatory response is mainly triggered by foreign body reaction after transplantation of a biomaterial and it is also a predictive factor for biocompatibility and the long term durability of the biomaterial at the defect site [45]. In literature, the in vivo effects of POSS nanoparticles were investigated for cardiovascular applications and clinical transplantation of the tracheobronchial airway to a patient [46-48]. Kannan et al. investigated (POSS-PCU) investigated the in vivo biocompatibility and biological stability of polyhedral oligomeric silsesquioxane (POSS) nanocomposite in a sheep model to observe the different effects of conventional siloxane and POSS incorporation. The implanted POSS-PCU nanocomposites exhibited no evidence of an inflammatory layer or capsule formation, even after 36 months of implantation [45].

However, in vivo effects of POSS nanocages have not been investigated for bone tissue engineering applications.
This study concerns the in vitro biological activity of POSS incorporated chitosan membranes. Thus, these results should be supported with further in vivo studies to investigate the possible effects and toxicity of POSS nanoparticles in metabolism due to its promising effects and to overcome the limitations of in vitro studies.

\section{Conclusions}

In this study, novel chitosan-Octa-TMA POSS composite membranes were prepared with solvent casting technique. AFM, FTIR, Protein adsorption, contact angle analyses and mechanical tests were applied to investigate the effects of POSS content on physical and chemical properties of composite membranes.

Our results showed that POSS incorporation increased the biomechanical properties of chitosan matrix up to $3 \%$. Above this concentrations, decrease was observed due to the possible agglomeration of POSS nanocages in chitosan matrix because of tendency of the particle-particle interactions. Although POSS incorporation did not affect the hydrophilicity of chitosan membranes, improved the surface area and roughness, swelling properties, and protein adsorption capacities of chitosan membranes which are important factors for osteoblast adhesion and proliferation. Furthermore, chitosan/POSS composite membranes did not show any cytotoxic effect on 3T3 and Saos-2 cells, possessing good cytocompatibility. In vitro cell culture studies indicated that POSS incorporation increased osteoblastic Saos-2 cell spreading and proliferation on membranes. In addition, ALP actitivty of Saos- 2 cells increased remarkably with an increase in POSS content for 14 and 21th day incubation periods. Hence, further in vivo research should be performed to consider this novel composite membrane as a potential biomaterial for guided bone tissue regeneration for oral and maxillofacial applications by concerning the enhanced properties and positive effects on in vitro biological activities.

Acknowledgements This study was supported by the Scientific Research Project of İzmir Institute of Technology (No.2011 IYTE02). The authors are grateful to İzmir Institute of Technology (Iztech) Biotechnology and Bioengineering Research and Application Center for fluorescence microscopy analyses and Centre for Material Research for AFM analysis. The authors thank to Assist Prof. Dr. Meltem Alper from Aksaray University for supplying SaOS-2 cell line.

\section{Compliance with ethical standards}

Conflict of interest The authors declare that they have no competing interests. 


\section{References}

1. Ghanbari H, de Mel A, Seifalian AM. Cardiovascular application of polyhedral oligomeric silsesquioxane nanomaterials: a glimpse into prospective horizons. Int $\mathrm{J}$ Nanomed. 2011;6:775-86.

2. Christenson EM, Anseth KS, Jeroen JJ, van den Beucken $P$, Chan CK, Ercan B, Jansen JA, Laurencin CT, Li W, Murugan R, Nair LS, Ramakrishna S, Tuan RS, Webster TJ, Mikos AG. Nanobiomaterial applications in orthopedics. J Orthop Res. 2006;25:11-22.

3. Ruiz-Hitzky E, Darder M, Aranda P. An introduction to bionanohybrid materials. Bio-inorganic hybrid nanomaterials strategies, syntheses, characterization and applications. Weinheim: Wiley-VCH; 2008. pp. 1-32.

4. Pielichowska K, Blazewicz S. Bioactive polymer/hydroxyapatite (nano) composites for bone tissue regeneration. Adv Polym Sci. 2010;232:97-207.

5. Razak SIA, Sharif NFA, Rahman WAWA. Biodegradable polymers and their bone applications: a review. Int Basic Appl Sci. 2012;12:31-49.

6. Kannan RY, Salacinski HJ, Butler PE, Seifalian AM. Polyhedral oligomeric sisesquioxane nanocomposites: the next generation material for biomedical applications. Acc Chem Res. 2005;38:879-84.

7. Zhao C, Yang X, Wu X, Liu X, Wang X, Lu L. Preparation and characterization of poly (methyl methacrylate) nanocomposites containing octavinyl polyhedral oligomeric silsesquioxane. Polym Bull. 2008;60:495-505.

8. Kim IY, Seo SJ, Moon HS, Yoo MK, Park IY, Kim BC, Cho CS. Chitosan and its derivatives for tissue engineering applications. Biotechnol Adv. 2008;26:1-21.

9. Chew SL, Wang K, Chai SP, Goh KL. Elasticity, thermal stability and bioactivity of polyhedral oligomeric silsesquioxanes reinforced chitosan-based microfibres. J Mater Sci Mater Med. 2011;22:1365-74.

10. Arca HÇ, Şenel S. Chitosan based systems for tissue engineering part 1: hard tissues. FABAD J Pharm Sci. 2008;33:35-49.

11. Di Martino A, Sittinger M, Risbud MV. Chitosan: a versatile biopolymer for orthopaedic tissue-engineering. Biomaterials. 2005;26:5983-90.

12. Wu CJ, Gaharwar AK, Schexnailder PJ, Schmidt G. Development of biomedical polymer-silicate nanocomposites: a materials science perspective. Materials. 2010;3:2986-3005.

13. Madhumathi K, Sudheesh Kumar PT, Kavya KC, Furuike T, Tamura H, Nair SV, Jayakumar R. Novel chitin/nanosilica composite scaffolds for bone tissue engineering applications. Int J Biol Macromol. 2009;45:289-92.

14. Puchol V, El Haskouri J, Latorre J, Guillem C, Beltrán A, Beltrán D, Amorós P. Biomimetic chitosan-mediated synthesis in heterogeneous phase of bulk and mesoporous silica nanoparticles. Chem Commun. 2009;19:2694-6.

15. Phillips SH, Haddad TS, Tomczak SJ. Developments in nanoscience: polyhedral oligomeric silsesquioxane (POSS)-polymers. Curr Opin Solid State Mater Sci. 2004;8:21-9.

16. Li G, Wang L, Ni H, Pittman CU Jr. Polyhedral oligomeric silsesquioxane (POSS) polymers and copolymers: a review. J Inorg Organomet Polym. 2001;11:123-54.

17. Wu X, Sun Y, Xie W, Liu Y, Song X. Development of novel dental nanocomposites reinforced with polyhedral oligomeric silsesquioxane (POSS). Dent Mater. 2009;26:456-62.

18. Bleha M, Tishchenko G, Pientka Z, Brus J. Effect of POSS ${ }^{\mathrm{TM}}$ functionality on morphology of thin hybrid chitosan membranes. Des Monomers Polym. 2004;7:25-43.
19. Pielichowski K, Njuguna J, Janowski B, Pielichowski J. Polyhedral oligomeric silsesquioxanes (POSS)-containing nanohybrid polymers. Adv Polym Sci. 2006;201:225-96.

20. Ghanbari H, Cousins BG, Seifalian AM. A nanocage for nanomedicine: polyhedral oligomeric silsesquioxane (POSS). Macromol Rapid Commun. 2011;32:1032-46.

21. Majumdar P, He J, Lee E, Kallam A, Gubbins N, Stafslien SJ, Chisholm BJ. Antimicrobial activity of polysiloxane coatings containing quaternary ammonium-functionalized polyhedral oligomeric silsesquioxane. J Coat Technol Res. 2010;7: 455-67.

22. An YZ, Flodin JT, Fu X, Kemp Z, Lichtenhan JD, Schwab JJ. U. S. Patent No. 7,572,872. Washington, DC: US Patent and Trademark Office; 2009.

23. Escoffier, L, Ganau, M, \& Wong, J. Commercializing nanomedicine: industrial applications, patents, and ethics. Florida, USA: CRC Press, 2015.

24. Ha Y-M, Amna T, Kim M-H, Kim H-C, Hassan MS, Khil M-S. Novel silicificated PVAc/POSS composite nanofibrous mat via facile electrospinning technique: potential scaffold for hard tissue engineering. Colloids Surf B. 2013;102:795-802.

25. Fernandez MD, Fernandez MJ, Cobos M. Effect of polyhedral oligomeric silsesquioxane (POSS) derivative on the morphology, thermal, mechanical and surface properties of poly(lactic acid)-based nanocomposites. J Mater Sci. 2016;51: 3628-42.

26. Hoven VP, Tangpasuthadol V, Angkitpaiboon Y, Vallapa N, Kiatkamjornwong S. Surface-charged chitosan: preparation and protein adsorption. Carbohydr Polym. 2007;68:44-53.

27. Hsieh W, Chang C, Lin S. Morphology and characterization of 3D micro-porous structured chitosan scaffolds for tissue engineering. Colloids Surf B. 2007;57:250-5.

28. Riss TL, Moravec RA, Niles AL, Duellman S, Benink HA, Worzella TJ, Minor L. Cell viability assays. 2016:1-47.

29. Costa-Pinto AR, Reis RL, Neves NM. Scaffolds based bone tissue engineering: the role of chitosan. Tissue Eng Part B. 2011;17:331-47.

30. Faucheux N, Schweiss R, Lützow K, Werner C, Groth T. Selfassembled monolayers with different terminating groups as model substrates for cell adhesion studies. Biomaterials. 2004; 25:2721-30.

31. Tzoneva R, Faucheux N, Groth T. Wettability of substrata controls cell-substrate and cell-cell adhesions. Biochim Et Biophys Acta. 2007;1770:1538-47.

32. Yuan Y, Lee TR. Contact angle and wetting properties. In Bracco G, Holst B, editors. Surface science techniques. Berlin, Heidelberg, Germany: Springer-Verlag; 2013. pp. 3-34.

33. Liu L, Hu Y, Song L, Nazare S, He S, Hull R. Combustion and thermal properties of OctaTMA-POSS/PS composites. J Mater Sci. 2007;42:4325-4333.

34. Marchessault RH, Ravenelle F, Zhu XX. Polysaccharides for drug delivery and pharmaceutical applications. Am Chem Soc. 2006.

35. Xu XY, Kim KM, Hanna MA. Chitosan-starch composite film: preparation and characterization. Ind Crops Prod. 2005; 21:185-92.

36. De Souza Costa-Junior E, Pereira Marivalda M, Mansur Herman S. Properties and cytocompatibility of chitosan films modified by blending with PVA and chemically crosslinked. J Mater Sci Mater Med. 2009;20:2553-61.

37. Rao KK, Naidu BVK, Subha MCS, Sairam M, Aminabhavi TM. Novel chitosan based $\mathrm{pH}$ sensitive interpenetrating network microgels fort the controlled release of cefadroxil. Carbohhydr Polym. 2006;66:333-44.

38. Ayers MR, Hunt AJ. Synthesis and properties of chitosan-silica hybrid aerogels. J Non-Cryst Solids. 2001;285:123-7. 
39. Pandis C, Madeira S, Matos J, Kyritsis A, Mano JF, Ribelles JLG. Chitosan-silica hybrid porous membranes. Mater Sci Eng C. 2014;42:553-61.

40. Zhao Y, Schiraldi DA. Thermal and mechanical properties of polyhedral oligomeric silsesquioxane (POSS)/polycarbonate composites. Polymer. 2005;46:11640-7.

41. Eshel H, Dahan L, Dotan A, Dodiuk H, Kenig S. Nanotailoring of nanocomposite hydrogels containing POSS. Polym Bull. 2008;61:257-65.

42. Putlyaev VI, Safronova TV. A new generation of calcium phosphate biomaterials: the role of phase and chemical compositions. Glass Ceram. 2006;63:99-102.

43. Terranova L, Dragusin DM, Mallet R, Vasile E, Stancu IC, Behets C, Chappard D. Repair of calvarial bone defects in mice using electrospun polystyrene scaffolds combined with $\beta$-TCP or gold nanoparticles. Micron. 2017;93:29-37.

44. Rezaie HR, Bakhtiari L, Öchsner A. Tissue response in biomaterials. In Biomaterials and their applications, SpringerBriefs in Materials. Cham, Switzerland: Springer; 2015. pp. 47-9.
45. Hartmann-Thompson, C (Ed.). Applications of polyhedral oligomeric silsesquioxanes (Vol. 3). New York, USA: Springer Science \& Business Media; 2011.

46. Kannan RY, Salacinski HJ, Ghanavi JE, Narula A, Odlyha M, Peirovi H, Seifalian AM. Silsesquioxane nanocomposites as tissue implants. Plast Reconstr Surg. 2007;119:1653-62.

47. Crowley C, Klanrit P, Butler CR, Varanou A, Platé M, Hynds RE, Janes SM. Surface modification of a POSS-nanocomposite material to enhance cellular integration of a synthetic bioscaffold. Biomaterials. 2016;83:283-93.

48. Jungebluth $\mathrm{P}$, Alici E, Baiguera S, Blomberg P, Bozóky B, Crowley C, Hermanson O. Tracheobronchial transplantation with a stem-cell-seeded bioartificial nanocomposite: a proof-of-concept study. Lancet. 2011;378:1997-2004. 